\section{To be found on the internet, try framing ocean conservation issues around 'sustainability'}

Mass media can help share environmental messages and inform audiences about public policy decisions that might otherwise only be known to those in the industry. The authors sought to determine how much marine-related news was being covered in the Chilean media: namely broadcast television, newspapers, and internet searches. The results indicated rather limited coverage of marine issues in the country. For some topics that were widely disseminated, through, positive public policy changes were implemented. This demonstrates the power of the press in the country and the importance of these issues reaching a wider audience.

Google Trends (https://trends.google.com/trends/) is a free service which allows anyone to track the popularity of search terms on the platform. Results from Google Trends are automatically normalized on a scale from 0 to 100 which allows one to compare how popular a search term was relatively, even if the total number of searches differs across time. The authors examined the Spanish-language translations for the search terms conservation, environment, biodiversity, fisheries, ecology, and sustainability in Google Trends between the years 2004 to 2015. Nearly all of the search terms saw a decrease in usage over the time period, indicating a low popularity with the average Chilean Googleuser. Sustainability was the only term that saw an increase in popularity. Framing marine issues around the term sustainability could help expose more internet users to the less popular topics, as in doing so, marine news would get tagged along in Google searches with the more tending term.

Newspapers and cultural television programs covering marine issues were rather infrequent between 2011 and 2013. One of the country's top newspapers devoted just $0.6 \%$ of their reporting to ocean issues. For broadcast television, the year 2012 saw no related programming whatsoever. Less than $7 \%$ of cultural programming for each of the other years were devoted to marine issues.

There is clearly a lot of room for improvement in the coverage of marine issues in the Chilean mass media. Framing these issues around topics people are interested in, like sustainability, could help local environmental organizations reach a larger audience.

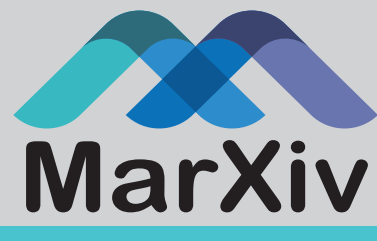

This is a summary of: Exploring marine environmental issues in the Mass Media: insights from television, newspaper and internet searches in Chile

Accessible at: https://marxiv.org/f3tk4

Authors: Gabriela Thompson-Saud, Stefan Gelcich, and José Barraza

Added to MarXiv: October 2018

Published: Ocean \& Coastal Management, 2018

Suggested Citation: To be found on the internet, try framing ocean conservation issues around 'sustainability'. ОСTO (2018). DOI: 10.31230/osf. io/pcmvr

See more MarXiv summaries at https://www.marxivinfo.org/ summaries

Join the MarXiv Summaries monthly newsletter at https:// oct.to/marxivsum

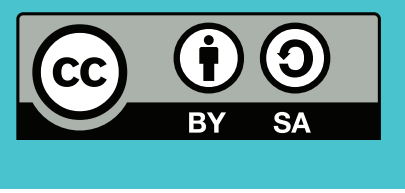

MarXiv is an ОСТO Initiative
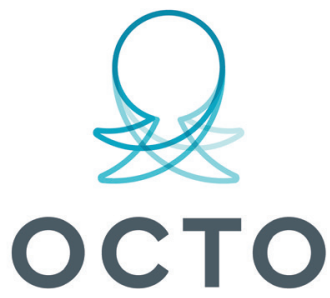

OPEN COMMUNICATIONS FOR THE OCEAN 